\title{
XLI. Induced radioactivity excited in air at the foot of waterfalls
}

\section{J.C. McLennan}

To cite this article: J.C. McLennan (1903) XLI. Induced radioactivity excited in air at the foot of waterfalls , Philosophical Magazine Series 6, 5:28, 419-428, DOI: 10.1080/14786440309462940

To link to this article: http://dx.doi.org/10.1080/14786440309462940

曲 Published online: 15 Apr 2009.

Submit your article to this journal $\widetilde{ }$

Џ Article views: 2

Q View related articles $\longleftarrow$

Citing articles: 1 View citing articles 5 
unsaturated solution, then along the boiling-point curve back to the point $\mathrm{T}_{/ /,}$, \&e. It is well worth while looking into. whether it is not possible, by mean: of such cycles, to disclose some new thermodynamic connexions between the different phenomena included in the above diagrams.

Davy-Faraday Laboratory of the Royal Institution, June 1902.

XLI. Induced Radioactivity Excited in Air at the Foot of Waterfalls. By J. C. MoLennan, Associate Professor of Physics, L'nirersity of Torouto*

\section{1.-Introduction.}

T $\mathrm{HE}$ fine drops of spray into which water is broken on pasing over waterfills was found by Lenard to communicate, on striking the wet rocks at the foot of the fall, a negative charge of electricity to the surrounding air and a positive charge to the water.

From a number of laboratory experiments with jets impinging on metal plates he obtained the same results with pure water, but found that the presence of any impurity greatly lessened the effect. With certain solutions-notably sodium chloride in water-the action weakened with an increase in the strength of the solution, and was finally reversed, a positive charge being communicated to the air and a negative charge to the liquid.

The splashing of rain he found imparted a negative electrification to the surrounding air, while the breaking of waves on the sea-shore electrified it positively.

The experiments of J. J. Thomson $\ddagger$ and of Elster and Geitel § have confirmed these observations, and, while showing that the sign and the amount of the electrification inparted varied both with the liquid and with the gas in which the splashing occurred, yet the splashing of pure water in air always gave a negative electrification.

A little over a year ago Elster and Geitel |f found that, if a negatively electrified wire were exposed for some hours in the open air or in a very large room, it became temporarily radioactive. Since then a number of observations have been made upon this effect, and the consensus of opinion appears to be that it is due to the presence in the atmosphere of some

* Communicated by Professor J. J. Thomson.

+ Lenard, Wied. Ann. xlvi. p. 584 (1892).

$\ddagger$ J. J. Thomson, 'Discharge of Electricity through Gases,' p. 17.

\$ Elster and Geitel, Wied. Ann. xlvii. p. 496 (1892).

II Elster.and Geitel, Phys. Zeit. No. 40, p. 590 (1901). 
peculiar constituent similar to the emanation from thorium, which has been shown by Rutherford * to induce radioactivity in any body with which it comes in contact, especially when that body is negatively electrified.

The difficulty of determining and of regulating the atmospheric conditions for observations upon this excited or induced radioactivity suggested the desirability of resorting, for purposes of experiment, to a locality where exceptional electrical conditions were known to exist permanently in the atmosphere. Niagara Falls, according to Lenard's results, is preeminently such a locality, and, through the kindness of the Hon. Thomas Walsh, Superintendent of the Niagara Falls National Park Reservation, the author was enabled in September last to carry out a short series of observations upon excited radioactivity at the foot of the Falls. The general result of the investigation was that during the course of the experiments the amount of radioactivity induced in a wire exposed at the foot of the Falls was found to be very much less than that in a wire exposed in the same manner in 'Toronto.

\section{2.-Apparatus.}

In these observations the measurements were made with a quadrant electrometer of the Mascart type as constructed by Carpentier. The silk suspension in the original apparatus was replaced by a phosphor-bronze strip less than 0.025 millimetre in thickness, which was attached at its upper end to an ebonite rod to secure insulation. The needle was kept charged by a battery of small storage-cells similar to those installed in the Reichsanstalt. The deflexions were ineasured by the movement of the image of an incandescent-lamp filament upon a transparent scale placed at a distance of one metre from the electrometer.

With a potential of 480 volt: applied to the needle, the sensibility of the instrument was such as to produce a deflexion of 1000 millims. on the scale for a potentialdifference of one volt between the quildrants. In measuring the induced radioactivity, bare copper-wire No. 24 was exposed in the open air by means of specially-constructed insulating supports (fig. 1) attached to a series of bamboo poles erected at convenient distances. The wire was charged by a small Toepler Holtz Electrical Machine driven by a water motor, which maintained a potential of from eight to ten thousand volts.

The insulator shown in fig. 1 consisted of a brass tube

* Rutherford, Phil. Marg, xlix. p. 1 \& p. 161 (1900). 
about 20 centimetres long, closed at one end and having a bellshaped opening at the other. Into this tube an ebonite rod was screwed which could be easily removed when it was necessary to renew its surface. Hooks fastened to the tube and to the ebonite rod provided for the support of the insulator and the suspension of the wire.

Fig. 1.

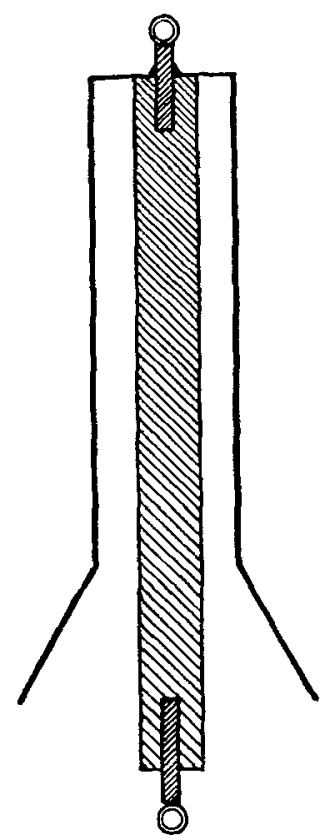

Fig. 2.

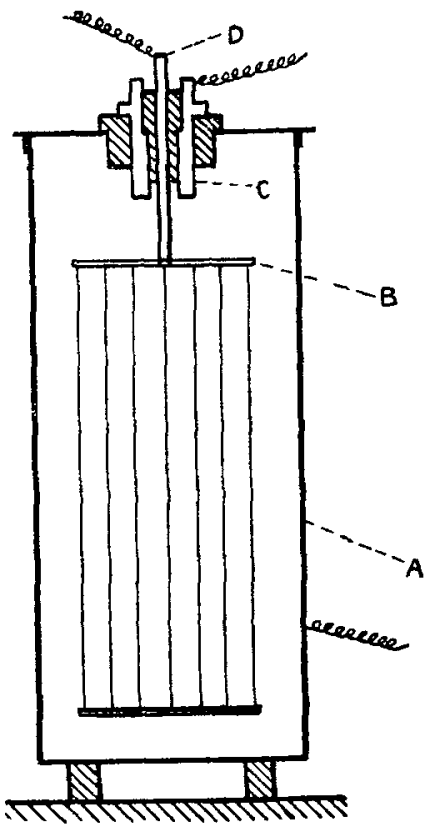

In the experiments at the foot of the Falls, it was found that with these insulators a wire could be easily maintained at a potential of 10,000 volts for hours even in a drenching spray.

The exposed wire was tested for induced radioactivity by means of the apparatus shown in fig. 2. A is a galvanized iron cylinder about $30 \mathrm{cms}$. high and $20 \mathrm{cms}$. in diameter, resting on an insulated platform and having a movable cover provided with a flanged opening into which was fitted an cbonite plug about five centimetres in diumeter. A brass tube $\mathrm{C}$ was passed through this plug and into it a second ebonite plug was tightly fitted. This second plug carried a brass rod D from which B a brass reel was suspended, and on this reel Plil. Mag. S. 6. Vol. 5. No. 28. April 1903. 2 F 
the wire to be tested was wound. The brass tube $\mathrm{C}$, which was earthed throughout the measurements, served as a guardring and prevented any leak from the vessel $A$ to the rod D across the ebonite plugs.

The saturation current due to spontaneous ionization of the air in the vessel having been first determined by connecting the supporting rod $D$ to the electrometer in the usual way and applying a potential of 100 volts to $A$, the exposed wire was then wound on the reel, inserted in the vessel, and the saturation current again ascertained. Any increase observed in the ionization current was taken as a measure of the radioactivity induced in the exposed wire.

As it was impossible, in setting up the apparatus in two different localities, to be certain that it was of exactly the same sensibility, a standard of ionization was deemed necessary for purposes of comparison. A radioactive substance which the writer had in his laboratory at the time of making the experiments was chosen, and a small quantity in a glass phial being found to give a constant ionization current when placed in a given position in the chamber $\mathrm{A}$, this current was adopted as a standard and the ionization currents measured in the various tests were expressed in terms of it.

$$
\text { 3.-Experiments. }
$$

Both before proceeding to Niagara, and after returning, a series of exposures was made in the quadrangle of the University at Toronto. Copper wires, approximately 30 metres long, were exposed for periods of two hours at a potential of 8000 to 10,000 volts on a number of days. After a wire had been exposed it was placed in the ionization chamber, the saturation current measured, and its radioactivity, thus ascertained, was expressed in terms of the standard radioactive substance.

The resulting values, taking the standard saturation current as unity, showed considerable variation in the amount of radioactivity excited, the highest value observed being 1.75 and the lowest $0 \cdot 6$. The intermediate values ranged between these limits, but were quite irregular and seemed to depend more upon the existence of wind and its velocity than other changes in the weather. The occurrence of showers did not exert a noticeable effect on the amount of radioactivity excited. It was frequently observed that exposures made in the morning gave greater induced radionctivity than those in the afternoon, but that exposures made after sunset gave values generally equal to, and sometimes greater, than those of the morning. 
The following numbers, which represent the observations made upon one day, are typical and show this variation:-

$\begin{array}{ccccc}\text { Exposare } & 9 \text { A.M.-11 A.M. } & \text { Excited radioactivity } & \cdot 8 \\ ", & 1 \text { P.M.—3 P.M. } & " & " & -6 \\ " & 6 \text { P.M.—-8 P.M. } & " & " & 1 \cdot 0 \\ " & 9 \text { P.M.-11 P.M. } & " & " & 1 \cdot 1\end{array}$

The observations were made in Toronto between Sept. 5th and 12th, and between the 19th and 23rd, those made at Niagara occupying the interval. The values in the two series at Toronto exhibited similar variations and were confined in both cases within the limits mentioned. The weather throughout, except for a few showers, was uniformly fine.

In conducting the experiments at Niagara Falls, the electrometer and its attachmen's were set up in the basement of the landing-station at the foot of the inclined railway. It was a large room having stone walls and a cement floor, and being fairly dry, was well suited for making the tests. The electrical machine which was intended for charging the wire was also located in this room, and the wire to be exposed was led from it out of a window and suspended in three stretches of about 30 metres each, the insulation being secured as already described.

The situation was admirably adapted for making the expostres, as the wire could be led within a metre or two of the vast mass of falling water. The first length of wire was generally enveloped in a very fine spray, that which surrounded the second was heavier, while the downpour upon the third resembled the heaviest rain.

A point of peculiar interest in connexion with the first exposure was that the wire, upon suspension in the spray, immediately ibecame negatively electrified to a potential of about 7500 volts. This voltage was maintained with but little variation both day and night during the period covered by the experiments, and the sign of the electrification was invariably negative.

The results of a number of tests with the different sections of the wire showed, that the removal of the third generally caused a drop in the potential of the remaining sections from 7500 volts to about 5500 volts, while the first section, when exposed alone, gave a potential varying from 3000 to 4000 volts. From this it was evident that the spray was the cause of the electrification, and that the potential of the wire was largely determined by its density.

On account of the permanency of this electrification of the $2 \mathrm{~F} 2$ 
exposed wire, the electrical machine necessary in the Toronto experiments was not employed.

In testing for induced radioactivity, the wire was exposed for periods of about two hours and was removed in sections, each section being replaced by a new length. The same method of testing was used as in Toronto, and the results expressed in terms of the standard radioactive substance.

Exposures were made on four different days with the following results, $\mathrm{A}, \mathrm{B}$, and $\mathrm{C}$ denoting the sections of the wire of which $A$ was that nearest the observing station, and $\mathrm{C}$ that nearest the Falls :-

\begin{tabular}{|c|c|c|}
\hline Date. & $\begin{array}{l}\text { Section of } \\
\text { wire tested. }\end{array}$ & $\begin{array}{l}\text { Induced Radioactivity. } \\
\text { Saturation current of } \\
\text { standard substance }=1 \text {. }\end{array}$ \\
\hline Sept. 12th ......... & $\begin{array}{l}\text { A. } \\
\text { B. } \\
\text { C. }\end{array}$ & $\begin{array}{c}0 \cdot 1 \\
0 \cdot 31 \\
\text { None observed. }\end{array}$ \\
\hline Sept. 13th ......... & $\begin{array}{l}\text { A. } \\
\text { B. } \\
\text { C. }\end{array}$ & $\begin{array}{l}\quad 0 \cdot 16 \\
\text { None observed. } \\
\text { Not expozed. }\end{array}$ \\
\hline Sept. 16th ......... & $\begin{array}{l}\text { A. } \\
\text { B. } \\
\text { C. }\end{array}$ & $\begin{array}{l}0 \cdot 13 \\
0 \cdot 14 \\
0 \cdot 11\end{array}$ \\
\hline Sept. 17tb ......... & $\begin{array}{l}\text { A. } \\
\text { B. } \\
\text { C. }\end{array}$ & $\begin{array}{c}0.15 \\
0.12 \\
\text { None observed. }\end{array}$ \\
\hline
\end{tabular}

From these numbers it will be seen that but little variation was observed in the radioactivity excited in the sections $A$ and $B$. In C, however, which was nearest the Falls, measurable radioactivity was present in only one of three exposures.

Ordinarily this section was drenched by masses of falling water in addition to being surrounded by fine spray such as enveloped the rest of the wire. But on Sept. 16th the air currents, during exposure, were such as to drive aside the sheets of water and permit only the fine spray to come in contact with the section.

As already stated the spray enveloping the section $B$ was generally heavier than that in contact with $A$, but the condition was not permanent as the spray was blown about by gusts of wind whose direction was continually changing in the gorge.

The chief interest attaching to the results was that the radioactivity excited was much less than that in Toronto. It 
will be noticed that the greatest amount of radioactivity observed at Niagara Falls was $0 \cdot 3$, while the least observed in Toronto during the period covered by the experiments was 06 . The numbers also show that on the average the radioactivity excited at Toronto was at least from six to seven times greater than that induced at the Falls.

The observations were not made in the two places at the same time, and a direct comparison is therefore impossible, but as there was no break in the weather during the progress of the experiments, and as the values found in Toronto before going to the Falls were almost the same as those obtained on returning, one is warranted in concluding that the air at the foot of the Falls permanently possesses less power to excite radioactivity than the air of localities at some distance.

While the experiments were in progress the spray was frequently examined for radioactivity. This was done by collecting a quantity, evaporating it, and testing the containing vessel. In no case was any trace of radioactivity observed.

Assuming then that excited radioactivity is caused by the presence in the atmosphere of some peculiar constituent, the experiments which have been described would seem to show that this constituent is present to a much less degree in the atmosphere in the neighbourhood of waterfalls than in places remote from them.

That it is possible to reduce the amount of this constituent present in the atmosphere is shown by some experiments recently performed in the Physical Laboratory at Toronto. The windows and doors of a large room, which had been well aired, were closed and, while of course they were not mado air-tight, it may be assumed, as they were close-fitting, that the quantity of outside air which they admitted was relatively small. An electrical machine at one end of the room was set in action and a number of zine disks attached to a wire leading from its negative terminal were suspended for an hour simultaneously at different points in the room. Upon testing these disks for radioactivity by the method employed by C. T. R. Wilson* it was found that radioactivity excited in the disks regularly increased with the distance from the machine.

It was also found, when a series of disks were consecutively exposed for an hour in a fixed position in the room after it had been well-aired and closed, that the radioactivity excited regularly diminished with the time. The admission of a considerable volume of fresh air, as by the opening of a * C. T. R. Wilson, Proc, Roy. Soc. vol, lxviii. p. 154, 
window, immediately caused an increase in the amount of radioactivity excited in the exposed disks. It was evident, therefore, that the electrical machine in action served as a means of removing from the atmosphere surrounding it the constituent upon whose presence the excited radioactivity depended.

In seeking for an explanation of the diminished radioactivity excited at the Falls, the experiments just described suggest the presence of an agency having an effect similar to that of the electrical machine on the air in the room.

The negative electrification of the wire when in the sprayarea pointed to the presence of this agency in the spray itself. The time at the writer's disposal did not permit of a direct investigation into the charge carried by the spray, but the negative electrification of the wire, which it will be remembered was always present and always increased as the wire was extended into the heavier spray, seemed to find its only explanation in a similar electrification of the spray. 'This being so, it follow's at once that the vast quantity of the spray produced by the Falls would act as a huge negatively-charged body in attracting to it from the surrounding atmosphere the constituent responsible for the excitation of induced radioactivity.

In this way a satisfactory explanation is afforded of the relatively small amount of induced radioactivity excited at the foot of the Falls. This explanation requires the spray itself to be radioactive, but when the enormous volume of the spray and the very limited amount of induced radioactivity observed in the locality are taken into account, together with the known decay of induced radioactivity, it would appear reasonable to conclude that experiments conducted with very much larger quantities of spray than those in the writer's tests would be necessary to obtain observable results.

From Lenard's observations one would bave expected a positive electrification to be developed on the exposed wire by the splashing of the spray, but the opposite was found. Some experiments on dropping water through ionized gases recently made by Schmauss ${ }^{*}$, give some aid in explaining this anomaly. $\mathrm{He}$ found that when water was dropped through air ionized by Röntgen rays, it acquired a negative charge from the gas, and he explained this fact by a reference to the experiments of Rutherford $\dagger$ and of Zeleny $\ddagger$, in which it was shown that

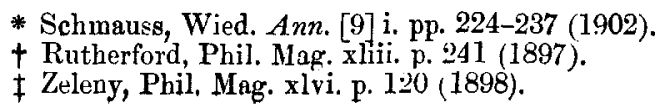


a stream of air, when it was ionized by Röntgen rays and directed against an insulated conductor, imparted to it a negative charge owing to the greater velocity of diffusion of the negative ions. These experiments, in which the gas was in motion and the insulated conductor at rest, Schmauss considered the converse of his own.

Now, in the experiments we are considering, we have water dropping through air which is known to be spontaneously ionized. From the results of Schmanss, we should expect the spray to take up a negative charge from the air. This, if sufficient to overcome the Lenard effect by which a positive charge is developed through the impact of the spray on the wire, should leave the wire negatively charged, and this was the uniform result of the observations.

\section{4.--Radioactive Rain and Snow.}

In order to ascertain, if possible, the effects of variations in the weather upon the radioactive state of the atmosphere the writer made a series of daily observations in the montt of November. During this period both rain and snow storms occurred. The falling of rain was not found to produce any marked change in the radioactive power of the atmosphere, although, as already shown by C.T. R. Wilson*, the rain itself when tested was active. The falling of snow, however, was accompanied by a very considerable drop in the value of the excited radioactivity. For example, on Nov. 25th the air was dry and cold, and the morning exposure gave a value of 0.92 , that for the afternoon exposure being $0 \cdot 66$. The next morning snow began to fall heavily, and an exposure was made in it for two hours. The resulting value for the excited radioactivity was $0 \cdot 3$. The snow-fall continued throughout the day, and the value for the afternoon exposure was again $0 \cdot 3$. This storm was general throughout Ontario, and the snow, which fell to a depth of about three inches, remained for some days on the ground and did not entirely disappear until Nov. 30th. Tests made for radioactivity in the interval showed values ranging from 0.2 to 0.4 . On Dec. 1st an exposure made about noon gave a value of 0.9 . On this day the weather was again mild and the snow had disappeared. Exposures made in the mornings of Dec. 2nd, 3rd, 4th, and 5th gave the values $0 \cdot 8,1 \cdot 1,0 \cdot 9,0 \cdot 9$ respectively.

The weather continued mild until Dec. 5th, when the temperature dropped below $0^{\circ} \mathrm{C}$. On Dec. 6 th the cold weather still prevailed and an exposure made from 1 to 3 o'clock in the afternoon gave a value of 0.92 . Shortly after $3 o^{\prime}$ clock

* C. T. R. Wilson, Proc, Camb. Phil. Soc, vol. xi. Pt. 6, p. 428. 


\section{Radioactivity Excited in Air at the Foot of Waterfalls.}

a light fall of fine snow began, which continued throughout the night. An exposure was made from 3.30 to 5.30 P.M., and also one from 9 to 11 P.M. The resulting value for the former was 0.2 , and for the latter 0.32 .

As the numbers just given indicate, the falling of snow on both occasions was accompanied by an immediate drop in the excited radioactivity. It will also be noticed that while the ground was covered with snow from the first fall the diminished activity continued. The snow on both occasions was collected as it fell, melted and evaporated, and the residne found to be highly radioative. Snow which fell in the first storm was tested after it had lain two days on the ground and was found still to possess about 1 per cent. of its original activity.

These results, it will be seen, lend support to the theory that the constituent of the atmosphere to which the excitation of radioactivity is due is an emanation from the earth's surface. It would also seem from the values found for the induced radioactivity that this emanation is cut off to a considerable extent when a wide area of the earth's surface is thickly covered with snow.

The limited number of observations made hardly justifies a definite conclusion as to the manner in which rain and snow become radioactive; but it is possible that water-vapour in moving through the air, whether in the form of clouds or otherwise, gains a negative charge in the same manner as the spray at the Falls, and consequently becomes radioactive. This view is supported by the results of some experiments recently made by the writer. Water-vapour was condensed from the atmosphere upon the surface of a number of cylin. ders containing a freezing-mixture of ice and salt. The water thus obtained was evaporated in a metallic tray and the residue tested for radioactivity. Such tests were made daily for a period of two weeks. In most of them no radioactivity was observed, but in several slight traces were noticeable, and on four occasions the radioactivity excited was very marked. Tho experiments were all conducted with equal care, and no cause was apparent for the different results of the observations.

The thanks of the writer are due to Mr. J. S. Plaskett, B.A., for assistance in conducting the experiments, which at Niagara were attended with considerable difficulty, and to Mr. J. C. Rothery, Superintendent of the Niagara Falls' Park and River Railway, for facilities afforded in transporting the apparatus.

Physical Laboratory, University of Toronto, December 8th, 1902. 